\title{
Optimal Financing Decision in a Contract Food Supply Chain with Capital Constraint
}

\author{
Ying Luo $\mathbb{D}$, ${ }^{1}$ Tianyu Deng, ${ }^{2}$ Qiang Wei $\mathbb{D},{ }^{3}$ Guoan Xiao, ${ }^{1}$ and Qihui Ling ${ }^{4}$ \\ ${ }^{1}$ School of Business, Hunan University of Science and Technology, Xiangtan 411100, China \\ ${ }^{2}$ Business School, Southwest Minzu University, Chengdu 610041, China \\ ${ }^{3}$ School of Management and Economics, University of Electronic Science and Technology of China, Chengdu 611731, China \\ ${ }^{4}$ School of Mechanical Engineering, Hunan University of Science and Technology, Xiangtan 422201, China \\ Correspondence should be addressed to Qiang Wei; wq_research@126.com
}

Received 29 April 2021; Accepted 21 June 2021; Published 10 July 2021

Academic Editor: Baogui Xin

Copyright ( 2021 Ying Luo et al. This is an open access article distributed under the Creative Commons Attribution License, which permits unrestricted use, distribution, and reproduction in any medium, provided the original work is properly cited.

\begin{abstract}
To solve the financing problem of the food producers, we consider a two-echelon contract food supply chain composed of a family farm with capital constraints and a food processing enterprise. With no capital constraints as the benchmark model, we analyze optimal decisions of the family farm and the food processing enterprise in the case of bank financing with bank participation only and bank financing with "government, bank, and insurance" coparticipation. Then, we discuss how the risk of yield uncertainty influences the optimal decisions and profits of the family farm and the food processing enterprise under different financing situation. Meanwhile, the reason why the government subsidizes agriculture is explored, and the policy of minimum purchase price of the food is initiated when the market price is too low. Finally, the numerical examples and sensitivity analysis are presented. The results show that the bank financing with "government, bank, and insurance" coparticipation improves the welfare of supply chain members more obviously than the bank financing with bank participation only; when the rice price is too low, the policy of minimum purchase price of food is initiated, which increases the revenue and the growing enthusiasm of the family farm; the profits of the family farm and the food processing enterprise will decrease as the risk of yield uncertainty increases in the case of bank financing, and the risk of yield uncertainty will be reduced for the family farm when bank financing with "government, bank, and insurance" coparticipation.
\end{abstract}

\section{Introduction}

As the Chinese saying goes "Hunger breeds discontentment," food security is self-evident to a country and is the foundation of national security. COVID-19 made the global food trade situation extremely severe in 2020, where 18 countries around the world banned food exports, and more than 20 countries increased their food reserves. Countries have paid more attention to food production to ensure their own food security since 2020. According to the National Bureau of Statistics of China, China's total food yield in 2020 was 669.49 million tons, which was 5.65 million tons more than in 2019, and the food yield has remained at more than 500 million tons since 2008 . However, the national conditions of limited arable land and large population require us to be mindful of crisis in times of peace and ensure national food security. The embryonic form of moderately scaled agricultural development has emerged in recent years with the development of urbanization in China, and many largescale operation entities represented by family farms, cooperatives, large specialized growers, and agricultural enterprises have emerged, which are the main force in the production of commodity food. The yield of the agricultural products is uncertain because its production is susceptible to natural conditions. At the same time, agricultural production materials, land transfer cost, labor cost, agricultural social service purchase cost, and purchase and maintenance cost of agricultural machines are all inseparable from financial support. However, there is an urgent need for efficient financing due to the lack of collateral for food growers 
and the short preparation time for crop production, but banks often hesitate to lend to reduce bad debts.

Supply chain finance refers to two or more organizations and external service providers in a supply chain that work together to create the value of all participating companies by planning, steering, and controlling the flow of financial resources at an interorganizational level $[1,2]$. Meanwhile, it is an effective way to solve the financing problem of smalland medium-sized enterprises (SMEs) [3-6], which is widely used in the manufacturing industry. We learn that the characteristics of family farms are similar to those of SMEs, so supply chain finance may be one of the feasible ways to solve their financing problem. However, food is an agricultural product that people must consume every day which has the attributes of a quasi-public product. The annual growing scale of food must be maintained above a certain safety level to ensure food security, and the yield is uncertain, which makes it different from the manufacturing supply chain. Government support is needed in food production and financing process, and many countries have corresponding domestic support policies for agricultural production in practice. In 2009, the agricultural loan mode of "government-bank-insurance" cooperation was firstly explored in Sanshui District, Foshan City, Guangdong Province, China. Up to now, Sanshui District has gone through 12 years of exploration, which has become the "golden key" to solve the problem of farmers' loans. In recent years, the agricultural loan mode of "government-bank-insurance" cooperation has also been promoted in China's Shandong, Hainan, and Fujian provinces and some other regions.

In this study, we discuss the financing decisions of the capital-constrained food supply chain and explore the following issues: is the mechanism of the choice of bank financing by the capital-constrained family farm consistent with the choice of bank financing by manufacturers in the manufacturing industry? Is it possible to simply apply the supply chain financing method which is relatively mature in the manufacturing industry to the contract food supply chain? Why are the food processing enterprises willing to choose contract farming? Why do the food processing enterprises provide guarantee for family farms when they choose bank financing? Why do governments need to intervene and support agricultural production? Why is the bank financing with "government, bank, and insurance" coparticipation an effective way to promote the financing for the family farm?

To answer these questions, we discuss a two-echelon contract food supply chain composed of a family farm with capital constraints and a food processing enterprise, where the food processing enterprise is the dominant and the family farm is the follower, and the family farm grows a single variety of rice. Assuming that the initial capital of the family farm is zero, short-term financing is required to prepare for production. Agricultural production is different from manufacturing production, which is susceptible to natural and climatic factors and has uncertain yield. Therefore, a yield random factor is introduced in this study. At the same time, the situation with no capital constraints is used as a benchmark model.
We analyze the mature supply chain financing model in the manufacturing industry where only banks participate at first. Then, after theoretically discussing why the government should subsidize agricultural production, we discuss the supply chain financing model in the case of "government, bank, and insurance" coparticipation, and the optimal decisions of the supply chain members are obtained. The conclusions show that financing improves the welfare of members of the supply chain, and the improvement is more significant in the case of bank financing with "government, bank, and insurance" coparticipation. However, the welfare of supply chain members fails to reach the welfare level of the benchmark model in either financing situation, which indicates that the cost generated in the financing process cannot be ignored.

The main contributions of this study are as follows: firstly, the yield uncertainty of agricultural supply chain is discussed, and yield random factor is introduced into the model, which is different from Huang \& Lin [7]. Agricultural production is greatly affected by natural conditions, so its yield uncertainty cannot be ignored. Secondly, the government participation in agricultural production is theoretically discussed, and the theoretical basis of government support for agricultural production is analyzed. Thirdly, the minimum purchase price policy of rice is considered in the model, which effectively improves the welfare of the family farm, thereby increasing their enthusiasm for growing rice. The bank financing with "government, bank, and insurance" coparticipation can significantly improve the welfare of the supply chain members, which will be an effective way to solve the financing problem of the family farm.

The study is organized as follows: we review the literature review in Section 2 and then present the research model description and hypotheses in Section 3. Section 4 discusses the benchmark model, followed by analysis of decisions of the supply chain members when bank financing with bank participation only and bank financing with "government, bank, and insurance" coparticipation in Section 5. The numerical simulation and sensitivity analysis are presented in Section 6. Finally, the study's conclusions, management implications, and some future research suggestions are summarized.

\section{Literature Review}

The study focuses on yield uncertainty, contract farming, and supply chain finance and agricultural supply chain finance. Thus, the review of early literature related to the study includes three main research streams: yield uncertainty, contract farming, and supply chain finance and agricultural supply chain finance.

2.1. Yield Uncertainty. He and Zhao [8] analyzed the optimal decisions of the multiechelon supply chain with uncertainty of demand and supply and coordinated the supply chain through the combination of wholesale price contract and return strategy. Ding and Wan [9] discussed bank financing and manufacturer financing in a capital-constrained supply 
chain and demonstrated that the pay back contract can coordinate the supply chain in these two financing situations, in which the supplier's yield is random. In order to solve the problem of random yield, the downstream members of the supply chain will choose multiple suppliers [10-14]. Because agriculture is greatly affected by natural conditions, the uncertainty of its yield cannot be ignored. At present, some literature on agricultural supply chain discusses the issue on yield uncertainty. Kazaz and Webster [15] investigated the optimal sales price and production quantity in the case of supply uncertainty in the agricultural industry. Huang and Lin [7] analyzed the dynamic game among the government, the bank, the companies, and farmers in the case of uncertain yield and made a case analysis of the new agricultural loan model of "government-bank-insurance" in Sanshui District, Foshan City, Guangdong Province, China, and put forward suggestions for improvement. Peng and Pang [16] discussed the optimal decision of a contract farming supply chain composed of a farmer, a supplier, and a distributor under government subsidy policies, where the farmer's yield is uncertain.

2.2. Contract Farming. Contract farming comes into being in order to cope with the uncertainty of agricultural yield and demand. There are some studies on the coordination of contract farming supply chain under uncertain yield and uncertain demand, where Ye et al. [17] consider a revenue sharing-production cost sharing-guaranteed money mechanism and Liu et al. [18] adopt the revenue-sharing-plusmargin contract. Zhang [19] pointed out that China's contract farming is very different from the experience of other developing countries and conducted a political economic analysis of contract farming in China's agricultural transformation. Wuepper and Sauer [20] argue that selfefficacy and social capital are decisive factors for farmers to successfully integrate into contract farming. Bellemare and Novak [21] explain the role of contract farming in structural transformation. Shi and Cao [22] discuss whether agricultural producers are willing to form an alliance in order to jointly deal with the uncertainty of yield in contract farming, which reveals why agricultural producers should form cooperatives, how they should cooperate, and how to design fair profit distribution policy. Ba et al. [23] show that the healthy development of contract farming will promote the upgrading of the national rice value chain. Zhang [24] explores a blockchain-supported contract farming financing solution, which aims to improve the credit system and information asymmetry, thereby increasing the reliability of transactions and reducing the cost of traditional agricultural order financing. There are also some research studies suggesting that farmers' incomes and other welfare are increased by contract farming [25-33].

\subsection{Supply Chain Finance and Agricultural Supply Chain} Finance. Supply chain finance is an effective way to solve the financing problems of SMEs [2-6]. It transforms the uncontrollable risks of a single enterprise into the controllable risks of the entire supply chain, effectively constructs a benign industrial ecology for banks, core enterprises, and SMEs, and promotes the interactive development of capital and industry in the real trade situation through the effective control of cash flow, information flow, and logistics. There is a lot of literature on bank financing and upstream and downstream financing within the supply chain [9, 34-37]. However, the supply chain of agricultural products, especially food, is different from that of industrial products, and the government will provide subsidies to guarantee its supply [38, 39]; therefore, agricultural supply chain financing will also involve government subsidies. Van Bergen et al. [40] discuss the supply chain finance arrangement in the procurement of agricultural products and compare the three management strategies of soft tolling, hard tolling, and contract farming, and the supply chain is fully coordinated under the contract farming strategy. Yan et al. [41] investigate the financing strategies of the fresh produce supply chain. Yi et al. [42] analyze a two-echelon agricultural supply chain consisting of an intermediary platform and a farmer with capital constraints, where the intermediary platform directly provides loans for the farmer or provide guarantees for the farmer in bank financing, and shows that the two financing support ways of the intermediary platform improve the welfare of the farmer and increase the total profit of the supply chain.

The above literature is elaborated from the perspectives of yield uncertainty, contract farming, and supply chain finance and agricultural supply chain finance. It can be seen that there is some literature related to yield uncertainty and contract agriculture, contract agriculture and supply chain finance, and yield uncertainty and supply chain finance. However, there is relatively few literature that combines yield uncertainty, contract agriculture, and supply chain finance, and only Huang and Lin [7] try it, which is most relevant to our study. Huang and Lin [7] mainly discuss the government subsidy mechanism in the contract farming supply chain financing in which the yield is uncertain, and the yield uncertainty is measured by the probability of occurrence in bumper years and disaster years in their study. We focus on the optimal decision of supply chain members in the contract food supply chain with capital constraints, and we introduce a random variable to measure the uncertainty of yield which is different from Huang and Lin [7]. At the same time, the food in our study is the bulk agricultural products with different characteristics from the general agricultural products, so we conduct a theoretical analysis of the government's participation in food production.

\section{Model Description and Assumptions}

A two-echelon food supply chain in a large food-producing county in China is designed, which consists of a family farm with insufficient working capital and a food processing enterprise with sufficient working capital. Among them, the food processing enterprise is the dominant player in the supply chain, and the family farm is the follower. The two parties play a Stackelberg game to determine their optimal decision, as shown in Figure 1. According to the contract, the 


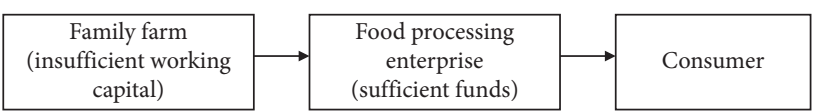

FIGURE 1: Two-echelon food supply chain structure.

family farm will grow a single variety of rice, which will be purchased by the food processing enterprise after being harvested and dried and then sold to consumers after being processed and further processed.

For simplicity, the initial capital of family farms is set as 0 which refers to Jing and Seidmann [43]. Through interviews with the staff of China Construction Bank, China Minsheng Bank, and other banks, we know that more and more upstream and downstream enterprises in the supply chain take the supply chain as a whole and take the credit of the core enterprises in the supply chain as the guarantee. The specific process is as follows: first, SMEs with capital constraints apply for loans from the bank. Then, the bank checks whether they are in the list according to the white list provided by the core enterprises. In this study, the core enterprise of the supply chain is the food processing enterprise, which dominates the whole supply chain, and the family farm is the follower. Second, the family farm applies for loans from the bank and provides the contract signed with the food processing enterprise. Then, according to a white list of approvals provided by the food processing enterprise, the bank disburses the loan to the food processing enterprise, which in turn disburses the loan to the family farm. Finally, the family farm obtains the loan to prepare for production.

The production of food is greatly affected by natural conditions, so its yield is highly random. At the same time, the property of food is quasi-public; therefore, the government will participate in regulation and control in order to ensure the country's food security. This study focuses on the bank financing decision of the food supply chain, which includes only the bank participation and "government, bank, and insurance" coparticipation.

The planned input of the family farm is $q$, which is affected by the growing area. $X$ is the random factor of yield and $X \in[\mathrm{d} 1, \mathrm{~d} 2]$ where $\mathrm{d} 1$ and $\mathrm{d} 2$ are constants. The density function of $X$ is $g(x)$, and its distribution function is $G(x)$, where meet $E(X)=\mu$ and $D(X)=\sigma^{2}$. Meanwhile, $\sigma^{2}$ is used to measure the risk of yield uncertainty. All the rice harvested from the family farm is purchased by food processing enterprises. $Q$ represents the actual yield of rice and satisfies $Q=q X$. In contrast to manufacturing economies of scale, agricultural production is diseconomies of scale [44], so we let the cost function $C(x)=c_{1} q+c q^{2}$, where $c_{1}$ represents the input cost of unit rice production, such as labor, fertilizer, seed, and pesticide, and $c$ represents the cost coefficient of production effort of the family farm. Meanwhile, we assume $c_{1}=0$ for simplicity. As mentioned before, food is a kind of staple agricultural products with the nature of quasi-public goods. When the market price of food is too low, the government entrusts the food processing enterprise with certain qualifications to purchase farmers' food at the minimum purchase price set by the government. $p$ is the market sales price of food, and its demand function is $p=m-\beta Q$, where $m$ represents the market size of rice and $\beta$ represents the price elasticity coefficient of the rice.

In order to reduce the debt repayment risk of the family farm and prevent the supply chain disruption caused by bankruptcy of the family farm, the core enterprise of the supply chain, namely, the food processing enterprise, will purchase an insurance, and the government will subsidize it. The economic explanation is to encourage social capital to invest in the food industry through financial subsidy. And some other symbols used in this study are summarized in Table 1.

Some assumptions are given as follows:

A1: it is assumed that both sides of the supply chain will abide by the order contract and there will be no breach of contract; that is, there is no moral hazard.

A2: the working capital of the family farm is set at 0 , and only the input cost of rice growing and the interest generated by financing are considered.

A3: the family farm, the food processing enterprise, the bank, and the government are risk-neutral and perfectly rational, and no information asymmetry such as Kouvelis and Zhao [35] and Luo et al. [37].

A4: as described in Kouvelis and Zhao [35], the residual value, out-of-stock cost, and holding cost of the product do not change the nature of the problem, and these costs are also ignored in this study, so the cost of the food processing enterprise only considers the purchase cost of rice, and the income of the food processing enterprise only considers rice processing and sale.

It can be seen from the assumptions that the members of the supply chain are risk-neutral, so their utility functions are the expected profit functions. For example, the optimal decision of the family farm is the input that maximizes its expected profit.

\section{No Financing: The Benchmark}

When the family farm has enough working capital, financing will no longer be needed, and the optimal decisions of the family farm and the food processing enterprise under this condition are obtained as follows.

The optimal decision for the family farm in this case is shown in the following equation:

$$
\max \pi_{f 0}=w_{0} q_{0} X-c q_{0}^{2} .
$$

The optimal decision for the food processing enterprise in this case is shown in the following equation:

$$
\begin{aligned}
& \max \pi_{m 0}=p_{0} q_{0} X-w_{0} q_{0} X=\left(m-\beta q_{0} X\right) q_{0} X-w_{0} q_{0} X \\
& \text { s.t. }\left\{\begin{array}{l}
q_{0}=q_{0}^{*}, \\
w_{0} \geq w .
\end{array}\right.
\end{aligned}
$$


TABLE 1: Introduction of the symbol.

\begin{tabular}{|c|c|}
\hline Symbol & Symbolic meaning \\
\hline $\bar{w}$ & The \\
\hline$q_{i}$ & $\begin{array}{l}q_{0}, q_{1} \text {, and } q_{2} \text {, respectively, represent the planned input of the family farm when there is no financing, when bank financing with } \\
\text { bank participation only, and when bank financing with "government, bank, and insurance" coparticipation }\end{array}$ \\
\hline$Q_{i}$ & $\begin{array}{r}Q_{0}, Q_{1} \text {, and } Q_{2} \text {, respectively, represent the actual yield of the fami } \\
\text { bank participation only, and when bank financing with }\end{array}$ \\
\hline$r_{i}$ & $\begin{array}{r}r_{1} \text { and } r_{2} \text {, respectively, represent the loan interest rate of the b } \\
\text { bank financing with "government, }\end{array}$ \\
\hline$w_{i}$ & $\begin{array}{l}w_{0}, w_{1} \text {, and } w_{2} \text {, respectively, represent the rice purchase price given by the } \\
\text { when bank financing with bank participation only, and when bank fi } \\
\text { coparticipation }\end{array}$ \\
\hline$p_{i}$ & $\begin{array}{r}p_{0}, p_{1}, \text { and } p_{2}, \text { respectively, represent the market pric } \\
\text { participation only, and when bank financin }\end{array}$ \\
\hline$R_{i}$ & $R_{1}$ and $R_{2}$, respectively, repres \\
\hline$Q_{t h i}$ & $\begin{array}{l}Q_{t h 1} \text { and } Q_{t h 2} \text {, respectively, represent the threshold of actuc } \\
\text { only and when bank financing with "government } \\
Q_{t h 2}\end{array}$ \\
\hline$r_{i}$ & $\begin{array}{r}r_{1} \text { and } r_{2} \text {, respectively, represent the interest rate from the } \\
\text { financing with "governmen }\end{array}$ \\
\hline$r_{f}$ & Ave \\
\hline$d_{t h i}$ & $\begin{array}{l}d_{t h 1} \text { and } d_{t h 2} \text {, respectively, represent the threshold of yield random } \\
\text { financing with bank participation only and in the case of bank financing } \\
\text { and } d_{t h 1}=\left(1+r_{1}\right) R_{1} / q_{1} w_{1}, d_{t h 2}\end{array}$ \\
\hline $\mathcal{J}$ & The bank loan subsidy $r$ \\
\hline$b$ & 1) \\
\hline$j$ & \\
\hline$\pi_{f i}$ & $\pi_{f 0}, \pi_{f 1}$, and $\pi$ \\
\hline$\pi_{m i}$ & $\begin{array}{l}\pi_{m 0}, \pi_{m 1} \text {, and } \pi_{m 2} \text {, respectively, represent } \\
\text { financing with bank participation only, }\end{array}$ \\
\hline & $\begin{array}{l}E \pi_{f 0}, E \pi_{f 1} \text {, and } E \pi_{f 2} \text {, respectively, represent the } \\
\text { financing with bank participation only, and whe }\end{array}$ \\
\hline & $\begin{array}{c}E \pi_{m 0}, E \pi_{m 1} \text {, and } E \pi_{m 2} \text {, respectively, represent the expected profits of the food processing enterprise when there is no } \\
\text { when bank financing with bank participation only, and when bank financing with "government, bank, and inst } \\
\text { coparticipation }\end{array}$ \\
\hline
\end{tabular}

Proposition 1. When there is no financing in the contract food supply chain, the optimal planned input of the family farm is $q_{0}^{*}=m \mu /\left[4 c-2 p\left(\sigma^{2}+\mu^{2}\right)\right]$, and the optimal purchase price of the food processing enterprise is $w_{0}^{*}=m c /\left[2 c-p\left(\sigma^{2}+\mu^{2}\right)\right]$, and the optimal purchase price of the food processing enterprise is $w$ when $w_{0}^{*}<w$.

Proposition 1 shows the optimal decisions of the family farm and the food processing enterprise in the case of sufficient working capital in the supply chain. At the same time, because of the quasi-public property of food, the food processing enterprise should purchase rice from the family farm at the minimum purchase price when $w_{0}<w$.

Meanwhile, the optimal expected profits of the family farm and the food processing enterprise can be obtained as follows:

$$
\begin{aligned}
& E \pi_{f 0}^{*}=\frac{m^{2} \mu^{2} c}{4\left[2 c-\beta\left(\sigma^{2}+\mu^{2}\right)\right]^{2}} \\
& E \pi_{m 0}^{*}=\frac{m^{2} \mu^{2}}{4\left[2 c-\beta\left(\sigma^{2}+\mu^{2}\right)\right]} .
\end{aligned}
$$

We can draw Corollary 1 by analyzing the relationship among the risk of yield uncertainty and the optimal decisions and expected profits of the supply chain members.

Corollary 1. When there is no financing in the contract food supply chain and the minimum purchase price policy is not considered, with the increase of the risk of yield uncertainty, the family farm will increase the scale of growing and the food processing enterprise will increase the purchase price, and the profits of the family farm and the food processing enterprise will increase accordingly.

Corollary 1 shows that when there is no financing in the supply chain, the family farm will expand the scale of growing with the increase of the risk of yield uncertainty. As the scale of growing expands, input costs of the family farm continue to increase. Once the risk of random events occurs, the family farm's harvest will be severely damaged, but the price will rise as demand exceeds supply, so the expected profit of the family farm will increase. Similarly, for the food processing enterprise, as the risk of yield uncertainty increases, and the market will be in short supply, so the food processing enterprises will increase the purchase price. Even 
if the risk random event occurs, the food processing enterprise will not lead to a sharp decline in profits; on the contrary, his profit will increase with the increase of the risk of yield uncertainty. In fact, it is ideal that members of the supply chain have no financial constraints no matter how much investment is increased. Therefore, the situation described in Corollary 1 does not exist in practice and is only for comparison.

\section{Bank Financing}

With the development of economy and society, the competition among enterprises in the 21 st century has transformed into competition among supply chains and it has become a consensus. There are many SMEs in the upstream and downstream of the supply chain. "Difficult to finance" and "expensive financing" are very common for SMEs, while solutions may be provided by supply chain finance. Due to the quasi-public product characteristics of food, this study analyzes two types of supply chain finance. In the first case, the supply chain members and the bank participate, and in the other case, the supply chain members and "government, bank, and insurance" participate together. Financing costs will be incurred, so in these two financing situations, the decision-making of the family farm and the food processing enterprise and how their welfare will change are the focus of our next analysis.

\subsection{Bank Financing with Bank Participation Only}

5.1.1. Financing Interest Rate When Bank Financing with Bank Participation Only. According to the previous assumption, the working capital of the family farm is 0 , and she needs to finance $R_{1}=c q_{1}^{2}$ from the bank and needs to repay $R_{1}\left(1+r_{1}\right)$ at the end of the period. When a random event occurs, the actual yield of the family farm is not enough to repay loans, so there is a risk of supply chain disruption. $Q_{t h 1}$ and $d_{t h 1}$, respectively, represent the threshold of the family farm' actual yield and the threshold of yield random when the supply chain disruptions. The yield of the family farm can repay the loan when $X \geq d_{t h 1}$.

As a rational decision-maker, the bank considers that the expected return on financing should be at least equal to the average return on the capital market when deciding whether to lend. The interest rate $r_{1}$ is designed based on the expected return on financing equal to the average return on the capital market as the following equation:

$$
\int_{\mathrm{d}_{1}}^{\mathrm{d}_{t h 1}} w_{1} Q_{1} g(x) \mathrm{d} x+\int_{\mathrm{d}_{t h 1}}^{\mathrm{d}_{2}} w_{1} Q_{t h} g(x) \mathrm{d} x=\int_{\mathrm{d}_{1}}^{\mathrm{d}_{t h 1}} w_{1} q_{1} x g(x) \mathrm{d} x+\int_{\mathrm{d}_{t h 1}}^{\mathrm{d}_{2}}\left(1+r_{1}\right) R_{1} g(x) \mathrm{d} x=R_{1}\left(1+r_{f}\right) .
$$

Proposition 2. When there is competition in the capital market, the financing rate $r_{1}$ will increase with the increase of the average rate of return $r_{f}$ in the capital market.

Proposition 2 shows that the financing rate $r_{1}$ will increase with the increase of the average rate of return $r_{f}$ in the capital market and the problems of "difficult financing" and "expensive financing" will become prominent. Therefore, bank financing of the contract supply chain with bank participation only could not solve the financing problem in the supply chain cause of the quasi-public property of food.

5.1.2. Decisions When Bank Financing with Bank Participation Only. In 1992, Christopher predicted that the competition among enterprises would transform into competition among supply chains in the 21 st century. Nowadays, supply chain financing has become the main way to solve the financing problems of SMEs. Family farms have similar characteristics to SMEs, so the study will employ supply chain financing to solve the financial constraints of the family farm. As shown in Figure 2, the process of bank financing with bank participation only is as follows: firstly, the food processing enterprise and the family farm who has capital constrains sign an order contract. Secondly, the family farm applies for loans from the bank and provides the order contract, the bank will make loans to the food processing enterprise after approval, and then it is offered to the family farm by the food processing enterprise. Thirdly, the food processing enterprise repays the loans and purchases all the rice according to the order after the harvest, and the remaining payment is delivered to the family farm by the food processing enterprise after deducting the principal and interest of the loan. If there is a random event of yield, the risk will be borne by the food processing enterprise.

The expected profit of the family farm when bank financing with bank participation only is shown in the following equation:

$$
E \pi_{f 1}=w_{1} q_{1} \mu-\left(1+r_{1}\right) c q_{1}^{2} .
$$

The profit of the food processing enterprise when bank financing with bank participation only is shown in the following equation: 


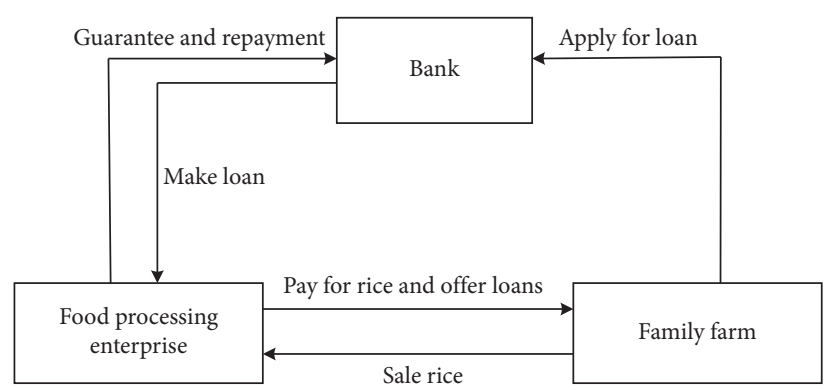

Figure 2: Operation diagram for bank financing with bank participation only.

$$
\begin{aligned}
& \pi_{m 1}=p_{1} q_{1} X-w_{1} q_{1} X=\left(m-\beta q_{1} X\right) q_{1} X-w_{1} q_{1} X=m q_{1} X-w_{1} q_{1} X-\beta q_{1}^{2} X^{2} \\
& \text { s.t. }\left\{\begin{array}{l}
q_{1}=q_{1}^{*}, \\
w_{1} \geq w .
\end{array}\right.
\end{aligned}
$$

The expected profit of the food processing enterprise when bank financing with bank participation only is shown in the following equation:

$$
E \pi_{m 1}=m q_{1} \mu-w_{1} q_{1} \mu-\beta q_{1}^{2}\left(\sigma^{2}+\mu^{2}\right)
$$

Proposition 3. When the family farm has capital constraint, optimal decisions when bank financing with bank participation only are as follows: the optimal planned input of the family farm is $q_{1}^{*}=m \mu /\left\{2\left[2 c\left(1+r_{1}\right)+\beta\left(\sigma^{2}+\mu^{2}\right)\right]\right\}$, and the optimal purchase price of the food processing enterprise is $w_{1}^{*}=m c\left(1+r_{1}\right) /\left[2 c\left(1+r_{1}\right)+\beta\left(\sigma^{2}+\mu^{2}\right)\right]$, and the optimal purchase price of the food processing enterprise is $w$ when $w_{1}^{*}<w$.

Proposition 3 shows the optimal decisions of the family farm and the food processing enterprise in the case of bank financing with bank participation only. At the same time, because of the quasi-public property of food, the food processing enterprise should purchase rice from the family farm at the minimum purchase price when $w_{0}<w$.

We can draw Corollary 2 by analyzing the relationship among yield uncertainty and the optimal decisions and expected profits of the supply chain members.

Meanwhile, the optimal expected profits of the family farm and the food processing enterprise in the case of bank financing with bank participation only can be obtained as follows:

$$
\begin{aligned}
E \pi_{f 1}^{*} & =\frac{m^{2} \mu^{2} c\left(1+r_{1}\right)}{4\left[2 c\left(1+r_{1}\right)+\beta\left(\sigma^{2}+\mu^{2}\right)\right]^{2}} . \\
E \pi_{m 1}^{*} & =\frac{m^{2} \mu^{2}}{4\left[2 c\left(1+r_{1}\right)+\beta\left(\sigma^{2}+\mu^{2}\right)\right]} .
\end{aligned}
$$

Corollary 2. When bank financing with bank participation only and the minimum purchase price policy is not considered, with the increase of the risk of yield uncertainty, the family farm will decrease the scale of growing and the food processing enterprise will decrease the purchase price, and the profits of the family farm and the food processing enterprise are all reduced as a result.

Corollary 2 shows that in the case of bank financing with bank participation only, the increase of the risk of yield uncertainty will cause the family farm to reduce the scale of growing, and the food processing enterprise will reduce the purchase price, which in turn will decrease the profits of the family farm and the food processing enterprise. Due to financial constraints, when the family farm applies for loans from the bank, the food processing enterprise provides guarantees and assumes joint and several liabilities. Therefore, they will become prosperous. The family farm and the food processing enterprise will make more conservative decisions. As the risk of yield uncertainty increases, the family farm reduces her growing scale and the food processing enterprise reduces his purchase price. In the end, the expectation profits of them will be reduced.

\subsection{Bank Financing with "Government, Bank, and Insurance"} Coparticipation. The previous section described the situation of bank financing in the food supply chain, in which the food processing enterprise gives guarantees to bear the risk when the family farm fail to repay the loan. Due to the quasipublic property of food, theoretical discussion on government support for agriculture will be arranged, and we will analyze bank financing with "government, bank, and insurance" joint participation in the next.

5.2.1. Theoretical Discussion on Government Support for Agriculture. Assume that the supply and demand curves of industrial goods and agricultural products are linear, and their supply and demand functions are as follows, where $p_{\text {ind }}$ and $p_{\text {agr }}$ are the prices of industrial products and agricultural products, respectively, $Q_{\text {ind }}$ and $Q_{a g r}$ are the trading volume of industrial products and agricultural products, respectively, $A, B, C$, and $D$ are all positive constant, $\beta_{\text {indd }}$ and $\beta_{\text {agrd }}$ 
are the demand elasticity coefficients of industrial products and agricultural products, respectively, and $\beta_{\text {inds }}$ and $\beta_{\text {agrs }}$ are the supply elasticity coefficients of industrial products and agricultural products, respectively:

$$
\begin{aligned}
& p_{\text {agr }}=A-\beta_{\text {agrd }} Q_{\text {agr }}, \\
& p_{\text {agr }}=B+\beta_{\text {agrs }} Q_{\text {agr }}, \\
& p_{\text {ind }}=C-\beta_{\text {indd }} Q_{\text {ind }}, \\
& p_{\text {ind }}=D+\beta_{\text {inds }} Q_{\text {ind }} .
\end{aligned}
$$

The equilibrium price and equilibrium transaction volume of agricultural products can be obtained as follows by combining equation (9) and equation (10):

$$
\begin{aligned}
p_{\mathrm{agr}} & =\frac{A \beta_{\mathrm{agrs}}+B \beta_{\mathrm{agrd}}}{\beta_{\mathrm{agrs}}+\beta_{\mathrm{agrd}}}, \\
\mathrm{Q}_{\mathrm{agr}} & =\frac{A-B}{\beta_{\mathrm{agrs}}+\beta_{\mathrm{agrd}}} .
\end{aligned}
$$

Similarly, the equilibrium price and equilibrium transaction volume of industrial products can be drawn as follows by combining equation (11) and equation (12):

$$
\begin{aligned}
p_{\text {ind }} & =\frac{C \beta_{\text {inds }}+D \beta_{\text {indd }}}{\beta_{\text {inds }}+\beta_{\text {indd }}}, \\
Q_{\text {ind }} & =\frac{C-D}{\beta_{\text {inds }}+\beta_{\text {indd }}},
\end{aligned}
$$

and then we assume that the supply-demand relationship of the two products remains unchanged, and their supply functions remain the same, while the demand for industrial products increases by $J$ units and the demand for agricultural products increases by $H$ units, so the demand curves for industrial products and agricultural products move to the right by the distance of $J$ and $H$, respectively. The new equilibrium prices of agricultural products and industrial products are as follows, where $p_{\text {ind }}^{\prime}$ and $p_{\text {arg }}^{\prime}$ are the prices of industrial products and agricultural products, respectively, when the demand increases:

$$
\begin{aligned}
& p_{\text {ind }}^{\prime}=\frac{(C+J) \beta_{\text {inds }}+D \beta_{\text {indd }}}{\beta_{\text {inds }}+\beta_{\text {indd }}}, \\
& p_{\text {arg }}^{\prime}=\frac{(A+H) \beta_{\text {agrs }}+B \beta_{\text {agrd }}}{\beta_{\text {agrs }}+\beta_{\text {agrd }}} .
\end{aligned}
$$

$\Delta p_{\text {ind }}$ and $\Delta p_{\text {agr }}$, respectively, indicate the increase in prices of industrial products and agricultural products, which is as follows:

$$
\begin{aligned}
& \Delta p_{\text {ind }}=\frac{J \beta_{\text {inds }}}{\beta_{\text {inds }}+\beta_{\text {indd }}}, \\
& \Delta p_{\text {agr }}=\frac{H \beta_{\text {agrs }}}{\beta_{\text {agrs }}+\beta_{\text {agrd }}} .
\end{aligned}
$$

The price increase difference between industrial products and agricultural products is shown in the following equation:

$$
\Delta p_{\text {ind }}-\Delta p_{\text {agr }}=\frac{(J-H) \beta_{\text {agrs }} \beta_{\text {inds }}+J \beta_{\text {inds }} \beta_{\text {agrd }}-H \beta_{\text {agrs }} \beta_{\text {indd }}}{\left(\beta_{\text {agrs }}+\beta_{\text {agrd }}\right)\left(\beta_{\text {inds }}+\beta_{\text {indd }}\right)} .
$$

Since the price elasticity of demand for agricultural products is less than that of most industrial products (except for salt, etc.), $\beta_{\text {indd }}>\beta_{\text {agrd }}$, the supply price elasticity of industrial products is greater than that of agricultural products, so $\beta_{\text {inds }}>\beta_{\text {agrs }}$, and the growth rate of demand for agricultural products is slower than that of industrial products, that is, $J>H$, so $\Delta p_{\text {ind }}-\Delta p_{\text {agr }}>0$ can be obtained. The above analysis indicates that the price of agricultural products is rising more slowly than that of industrial products. Therefore, farmers cannot exchange the same amount of agricultural products for the same amount of industrial products, which requires the government to support agricultural products. In fact, many countries currently have domestic support policies for agricultural production.

\subsubsection{Financing Interest Rate When Bank Financing with} "Government, Bank, and Insurance" Coparticipation. Similar to the case of bank financing with bank participation only, the working capital of the family farm is 0 , and she needs to finance $R_{2}=c q_{2}^{2}$ from the bank and needs to repay $R_{2}\left(1+r_{2}\right)$ at the end of the period. In the case of bank financing with "government, bank, and insurance" coparticipation, $Q_{t h 2}$ and $d_{t h 2}$, respectively, represent the threshold of the family farm's actual yield and the threshold of yield random when the supply chain disruptions, the yield of the family farm can repay the loan when $X \geq d_{t h 2}$, and the interest rate $r_{2}$ is designed based on the expected return on financing equal to the average return on the capital market as

$$
\int_{\mathrm{d}_{1}}^{\mathrm{d}_{t h 2}} w_{2} Q_{2} g(x) \mathrm{d} x+\int_{\mathrm{d}_{t h 2}}^{\mathrm{d}_{2}} w_{2} Q_{t h 2} g(x) \mathrm{d} x=\int_{\mathrm{d}_{1}}^{\mathrm{d}_{t h 2}} w_{2} q_{2} x g(x) \mathrm{d} x+\int_{\mathrm{d}_{t h 2}}^{\mathrm{d}_{2}}\left(1+r_{2}\right) R_{2} g(x) \mathrm{d} x=R_{2}\left(1+r_{f}\right)
$$


Just like Proposition 2, the financing rate $r_{2}$ will increase with the increase of the average rate of return $r_{f}$ in the capital market, and the above analysis indicates that the government will support agricultural products, so loan interest discount and insurance subsidy will be provided by the government in this study.

5.2.3. Decisions When Bank Financing with "Government, Bank, and Insurance" Coparticipation. The process of bank financing with "government, bank, and insurance" coparticipation is as follows: firstly, the food processing enterprise and the family farm who has capital constrains sign an order contract. Secondly, the family farm applies for loans from the bank and provides the order contract, the bank will make loans to the food processing enterprise after approval, and then it is offered to the family farm by the food processing enterprise. Thirdly, the food processing enterprise purchases loan guarantee insurance, bank submits interest discount applications to the government, and the insurance company submits premium subsidy applications to the government. Fourthly, the food processing enterprise repays the loans and purchases all the rice according to the order after the harvest, and the remaining payment is delivered to the family farm by the food processing enterprise after deducting the principal and interest of the loan. If there is a random event of yield, claim settlement will be started, and the risk of yield uncertainty will be borne by the government, banks, and insurance together. The specific process shown is in Figure 3.

The expected profit of the family farm when bank financing with "government, bank, and insurance" coparticipation is shown in the following equation:

$$
E \pi_{f 2}=w_{2} q_{2} \mu-c q_{2}^{2}-(1-s) r_{2} c q_{2}^{2} .
$$

The profit of the food processing enterprise when bank financing with "government, bank, and insurance" coparticipation is shown in the following equation:

$$
\begin{aligned}
\pi_{m 2}= & p_{2} q_{2} X-w_{2} q_{2} X-b(1-j)\left(1+r_{2}\right) c q_{2}^{2} \\
& \text { s.t. }\left\{\begin{array}{l}
q_{2}=q_{2}^{*}, \\
w_{2} \geq w .
\end{array}\right.
\end{aligned}
$$

The expected profit of the food processing enterprise when bank financing with "government, bank, and insurance" coparticipation is shown in the following equation:

$$
E \pi_{m 2}=m q_{2} \mu-w_{2} q_{2} \mu-\beta q_{2}^{2}\left(\sigma^{2}+\mu^{2}\right)-b(1-j)\left(1+r_{2}\right) c q_{2}^{2} .
$$

Proposition 4. When the family farm has capital constraint, optimal decisions when bank financing with "government, bank, and insurance" coparticipation are as follows: the optimal planned input of the family farm satisfies $q_{2}^{*}=(1 / 2) m \mu /\left\{2 c\left[1+(1-s) r_{2}\right]+\beta\left(\sigma^{2}+\mu^{2}\right)+b(1-j)(1+\right.$ $\left.\left.r_{2}\right) c\right\}$, the optimal purchase price of the food processing enterprise satisfies $w_{2}^{*}=m c\left[1+(1-s) r_{2}\right] /\left\{2 c\left[1+(1-s) r_{2}\right]+\right.$ $\left.\beta\left(\sigma^{2}+\mu^{2}\right)+b(1-j)\left(1+r_{2}\right) c\right\}$, and the optimal purchase price of the food processing enterprise is $w$ when $w_{2}^{*}<w$.

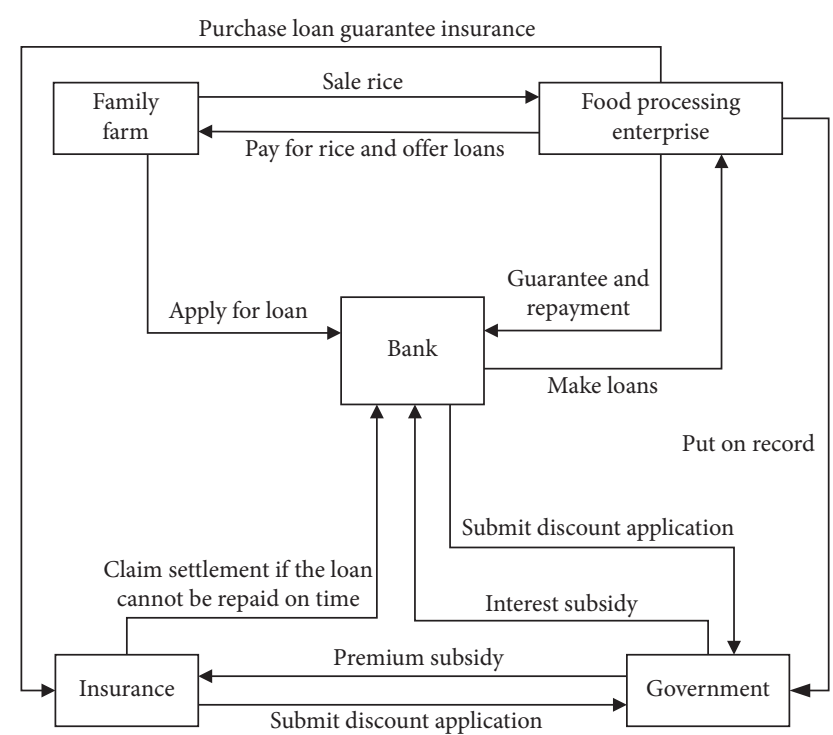

Figure 3: Operation diagram for bank financing with "government, bank, and insurance" coparticipation.

Proposition 4 shows the optimal decisions of the family farm and the food processing enterprise in the case of bank financing with "government, bank, and insurance" coparticipation. At the same time, because of the quasi-public property of food, the food processing enterprise should purchase rice from the family farm at the minimum purchase price when $w_{0}<w$.

Meanwhile, the optimal expected profits of the family farm and the food processing enterprise in the case of bank financing with "government, bank and insurance" coparticipation can be obtained as follows:

$$
\begin{aligned}
& E \pi_{f 2}^{*}=\frac{m^{2} c \mu^{2}\left[1+(1-s) r_{2}\right]}{4\left\{2 c\left[1+(1-s) r_{2}\right]+\beta\left(\sigma^{2}+\mu^{2}\right)+b(1-j)\left(1+r_{2}\right) c\right\}^{2}}, \\
& E \pi_{m 2}^{*}=\frac{\mu^{2} m^{2}}{4\left\{2 c\left[1+(1-s) r_{2}\right]+\beta\left(\sigma^{2}+\mu^{2}\right)+b(1-j)\left(1+r_{2}\right) c\right\}} .
\end{aligned}
$$

Corollary 3 can be drawn by analyzing the relationship among yield uncertainty and the optimal decisions and expected profits of the supply chain members.

Corollary 3. When bank financing with "government, bank, and insurance" coparticipation and the minimum purchase price policy is not considered, with the increase of the risk of yield uncertainty, the family farm will decrease the scale of growing and the food processing enterprise will decrease the purchase price, and the profits of the family farm and the food processing enterprise are all reduced as a result.

Corollary 3 shows that in the case of bank financing with "government, bank, and insurance" coparticipation, the increase of the risk of yield uncertainty will cause the family farm to reduce the scale of growing, and the food processing enterprise will reduce the purchase price, which in turn will 
decrease the profits of the family farm and the food processing enterprise. By comparing Corollary 1-3, it can be seen that when there are financial constraints in the supply chain, the decision of supply chain members to deal with the yield uncertainty is opposite. The possible reason is that financial constraints make the supply chain members more conservative.

\section{Numerical Examples and Sensitivity Analysis}

The above propositions and corollaries will be further verified by the numerical examples, and the sensitivity analysis is also carried out. As mentioned earlier, the parameters are set as follows: $m=5000, \beta=0.5, c=100$, $w=2335.3333, d_{1}=5-a, d_{2}=5+a, X \sim U[5-a, 5+a]$, $\mu=5, \quad \sigma^{2}=a^{2} / 3, \quad r_{f}=0.0002, \quad s=0.05, \quad b=0.025$, and $j=0.8$. In Table 2 and $3, \Delta q_{1}$ represents the planned input difference before and after the launch of the minimum purchase price policy in the case of bank financing with bank participation only and $\Delta q_{2}$ represents the difference of planned investment before and after the launch of the minimum purchase price policy in the case of bank financing with "government, bank, and insurance" coparticipation. The meanings of $\Delta E \pi_{f 1}, \Delta E \pi_{f 2}, \Delta E \pi_{m 1}$ and $\Delta E \pi_{m 2}$ are similar and will not be repeated.

6.1. No Financing: The Benchmark. Given the relevant parameters, the optimal decision and optimal expected profit of each member in the contract food supply chain can be obtained easily, which verifies Proposition 1. At the same time, as we can see from Table 2, as the risk of yield uncertainty increases, the family farm will increase the growing scale, and the food processing enterprise will increase the purchase price. Meanwhile, the profits of the family farm and the food processing enterprise will increase as the risk of yield uncertainty increases, which proves Corollary 1.

6.2. Bank Financing with Bank Participation Only. As can be seen from Figure 4, when there is competition in the capital market, the financing rate $r_{1}$ will increase with the increase of the average rate of return $r_{f}$ in the capital market, which verifies Proposition 2. This indicates that, in the case of bank financing with bank participation only, given relevant parameters, there is a single optimal input amount for the family farm to maximize her profit and a single optimal purchase price for the food processing enterprise to maximize his profits. However, the financing rate $r_{1}$ will increase with the increase of the average rate of return $r_{f}$ of the capital market, which will make financing more and more expensive, and the financing problem will be more and more difficult to solve in the case of bank financing with bank participation only. Therefore, it is urgent for the government to participate and offer solutions.

As shown in Table 3, it is easy to obtain the optimal decision and optimal expected profit of each member of the contract food supply chain when given corresponding parameters in the case of bank financing with bank participation only, which verifies Proposition 3.
TABLE 2: Sensitivity analysis of the risk of yield uncertainty without capital constraints.

\begin{tabular}{lccccc}
\hline$a$ & $\sigma^{2}$ & $q_{0}$ & $w_{0}$ & $E \pi_{f 0}$ & $E \pi_{m 0}$ \\
\hline 0.1 & 0.0000 & 63.29 & 2531.65 & 432825.59 & 995527.51 \\
0.5 & 0.0833 & 63.29 & 2531.69 & 432888.77 & 996245.41 \\
1 & 0.3333 & 63.31 & 2532.36 & 433839.72 & 998795.45 \\
1.5 & 0.7500 & 63.38 & 2535.26 & 437996.93 & 1004107.97 \\
2 & 1.3333 & 63.58 & 2543.09 & 449491.14 & 1013852.23 \\
2.5 & 2.0833 & 63.99 & 2559.77 & 475260.00 & 1030390.09 \\
3 & 3.0000 & 64.77 & 2590.67 & 528157.11 & 1056314.22 \\
3.5 & 4.0833 & 66.08 & 2643.22 & 636713.16 & 1091786.20 \\
4 & 5.3333 & 68.20 & 2728.10 & 881843.28 & 1118961.14 \\
4.5 & 6.7500 & 71.54 & 2861.74 & 1598258.54 & 1198933.35 \\
5 & 8.3333 & 76.79 & 3071.67 & 5981214.56 & 1360822.31 \\
\hline
\end{tabular}

When $w_{1}<w=2335.33$, the optimal purchase price is $w$ as mentioned before. It can be drawn directly that after the minimum purchase price is implemented from the $7 \mathrm{th}, 8 \mathrm{th}$, and 9th columns of Table 3, the optimal input amount of the family farm is more than when the minimum purchase price policy is not activated, and the expected profit of the family farm is higher than when the minimum purchase price policy is not activated. Therefore, the welfare of the family farm is improved after the implementation of the minimum purchase price policy, which explains why the minimum purchase price policy is initiated. At the same time, the expected profit of the food processing enterprise after starting the minimum purchase price policy is lower than that without starting the minimum purchase price policy, and when the risk of yield uncertainty is the largest, the expected profit decreases more. This is because the minimum purchase price is higher than the market price, and the profit of the food processing enterprise is bound to decrease.

6.3. Bank Financing with "Government, Bank, and Insurance" Coparticipation. As shown in Table 4, it is easy to obtain the optimal decision and optimal expected profit of each member of the contract chain after the corresponding parameters are given in the case of bank financing with "government, bank, and insurance" coparticipation, which verifies Proposition 4. Proposition 4 shows that, given relevant parameters, there is a single optimal input amount for the family farm to maximize their profits and a single optimal purchase price for the food processing enterprise to maximize their profits in the case of bank financing with "government, bank, and insurance" coparticipation.

The minimum purchase price is implemented when $w_{2}<w=1950$. It can be observed intuitively that after the minimum purchase price is implemented from the $7 \mathrm{th}, 8 \mathrm{th}$, and 9th columns of Table 4, the optimal input amount of the family farm is greater than when the minimum purchase price policy is not activated. The expected profit of the family farm is much higher than when the minimum purchase price policy is not initiated. Therefore, the implementation of the minimum purchase price policy greatly increases the profit of the family farm in the case of bank financing with "government, bank, and insurance" coparticipation, which 
TABLE 3: Sensitivity analysis of the risk of yield uncertainty in the case of bank financing with bank participation only.

\begin{tabular}{lcccccccc}
\hline$a$ & $\sigma^{2}$ & $q_{1}$ & $w_{1}$ & $E \pi_{f 1}$ & $E \pi_{m 1}$ & $\Delta q_{1}$ & $\Delta E \pi_{f 1}$ & $\Delta E \pi_{m 1}$ \\
\hline 0.0 & 0.0000 & 59.43 & 2356.40 & 341842.30 & 727923.19 & 0.00 & 0.00 \\
0.5 & 0.0833 & 59.03 & 2355.25 & 341005.74 & 727370.26 & 0.00 & 0.00 & 0.00 \\
1.0 & 0.3333 & 58.72 & 2353.78 & 340644.07 & 726486.84 & 0.00 & 0.00 \\
1.5 & 0.7500 & 58.18 & 2350.18 & 339857.66 & 726302.35 & 0.00 & 0.00 & 0.00 \\
2.0 & 1.3333 & 58.12 & 2346.95 & 339020.23 & 725518.91 & 0.00 & 0.00 & 0.00 \\
2.5 & 2.0833 & 58.04 & 2342.82 & 338922.41 & 725456.36 & 0.00 & 0.00 \\
3.0 & 3.0000 & 57.95 & 2337.76 & 338655.53 & 723118.56 & 0.00 & 0.00 & 0.00 \\
3.5 & 4.0833 & 56.84 & 2331.71 & 337308.55 & 721307.07 & 3.11 & 914.61 & -3267.77 \\
4.0 & 5.3333 & 55.69 & 2325.19 & 334993.40 & 719355.91 & 5.19 & 3296.55 & -7131.37 \\
4.5 & 6.7500 & 54.51 & 2317.76 & 332590.86 & 717483.64 & 8.32 & 5765.19 & -8086.41 \\
5.0 & 8.3333 & 53.30 & 2309.29 & 330296.79 & 715146.61 & 10.56 & 8026.28 & -9348.95 \\
\hline
\end{tabular}

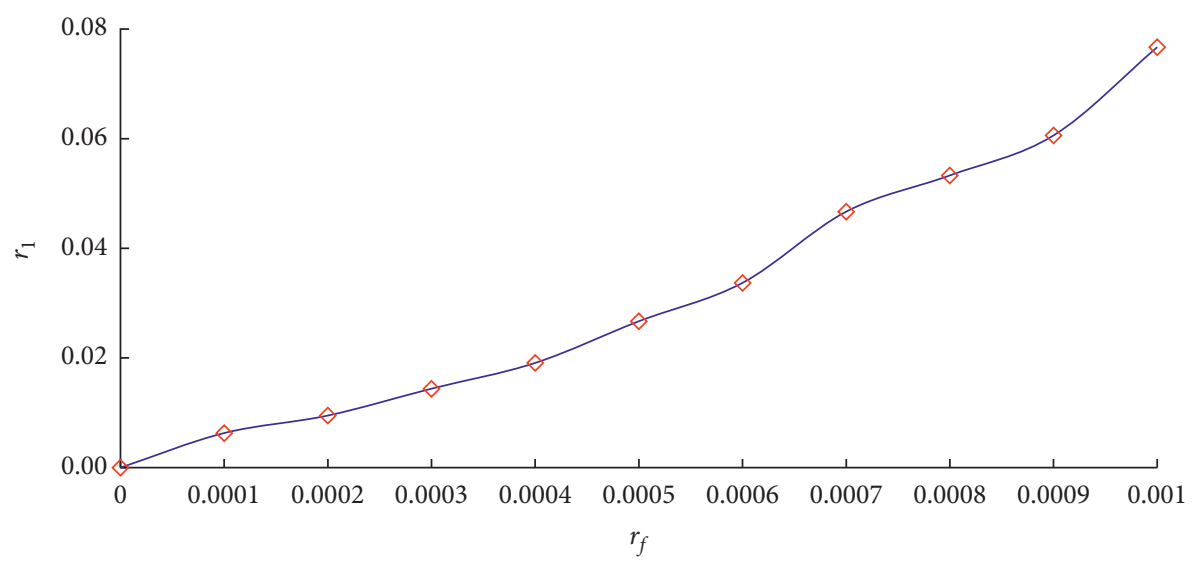

FIGURE 4: The relationship between $r_{1}$ and $r_{f}$ when $a=3$.

TAвLE 4: Sensitivity analysis of the risk of yield uncertainty in the case of bank financing with "government, bank, and insurance" coparticipation.

\begin{tabular}{ccccccccc}
\hline$a$ & $\sigma^{2}$ & $q_{2}$ & $w_{2}$ & $E \pi_{f 2}$ & $E \pi_{m 2}$ & $\Delta q_{2}$ & $\Delta E \pi_{f 2}$ & $\Delta E \pi_{m 2}$ \\
\hline 0.0 & 0.0000 & 70.49 & 2348.01 & 359977.62 & 738357.53 & 0.00 & 0.00 \\
0.5 & 0.0833 & 68.03 & 2347.53 & 352940.28 & 734426.84 & 0.00 & 0.00 & 0.00 \\
1.0 & 0.3333 & 65.41 & 2346.13 & 349615.43 & 732971.69 & 0.00 & 0.00 \\
1.5 & 0.7500 & 63.39 & 2343.77 & 347115.03 & 731838.19 & 0.00 & 0.00 & 0.00 \\
2.0 & 1.3333 & 62.82 & 2340.56 & 344944.74 & 730981.93 & 0.00 & 0.00 & 0.00 \\
2.5 & 2.0833 & 61.23 & 2336.44 & 341113.37 & 729045.04 & 0.00 & 0.00 & 0.00 \\
3.0 & 3.0000 & 59.12 & 2331.42 & 338754.31 & 728798.02 & 7.10 & 1138.35 \\
3.5 & 4.0833 & 58.01 & 2325.46 & 338259.16 & 727146.11 & 10.25 & 2870.92 & -1052.05 \\
4.0 & 5.3333 & 57.81 & 2318.82 & 337152.17 & 726679.14 & 13.41 & 4791.34 & -6192.66 \\
4.5 & 6.7500 & 57.59 & 2311.34 & 335795.99 & 723919.02 & 17.60 & 6944.22 & -7057.56 \\
5.0 & 8.3333 & 57.37 & 2302.99 & 332311.31 & 721137.16 & 23.81 & 9344.26 & -8141.48 \\
\hline
\end{tabular}

further explained why to adopt the minimum purchase price policy.

Combining the 7th, 8th, and 9th columns of Tables 3 and 4 , we can obtain that after the implementation of the minimum purchase price when the market price is too low, the expected profit reduction of the food processing enterprise in the case of bank financing with "government, bank, and insurance" coparticipation is less than that of bank financing with bank participation only. The reason is that the government and insurance companies share part of the risks for the food processing enterprise in the case of bank financing with "government, bank, and insurance" coparticipation. Meanwhile, the increase in input amount and expected profit of the family farm in the case of bank financing with "government, bank, and insurance" coparticipation are both greater than those of bank financing with bank participation only. The reason is that the yield uncertainty of the family farm is reduced in the case of bank financing with "government, bank, and insurance" coparticipation. 


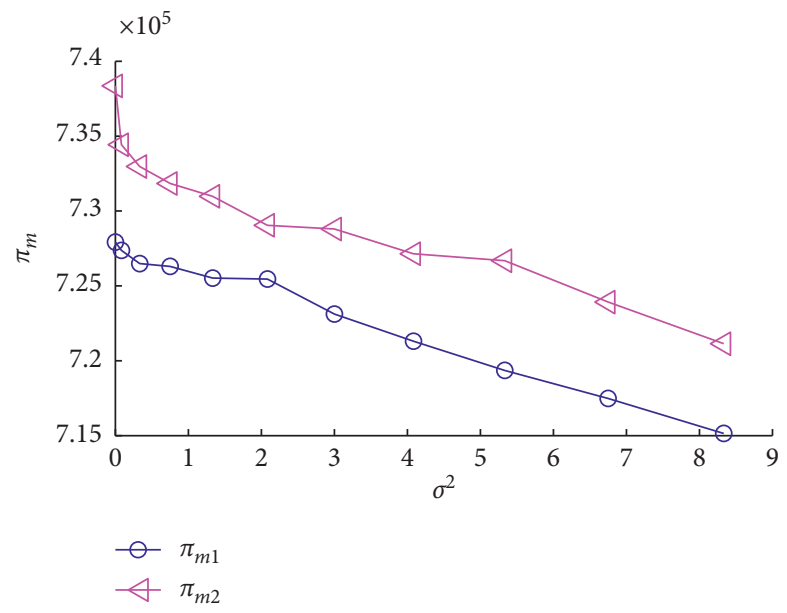

(a)

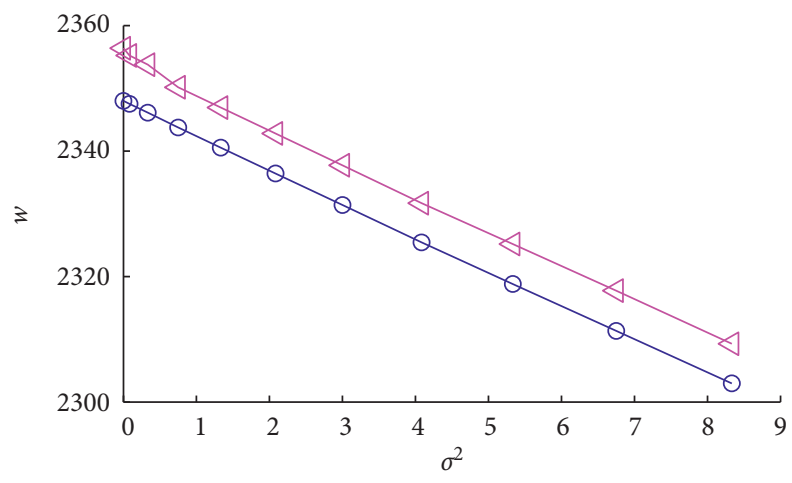

$\begin{array}{ll}\bigcirc & w_{1} \\ \varangle & w_{2}\end{array}$

(c)

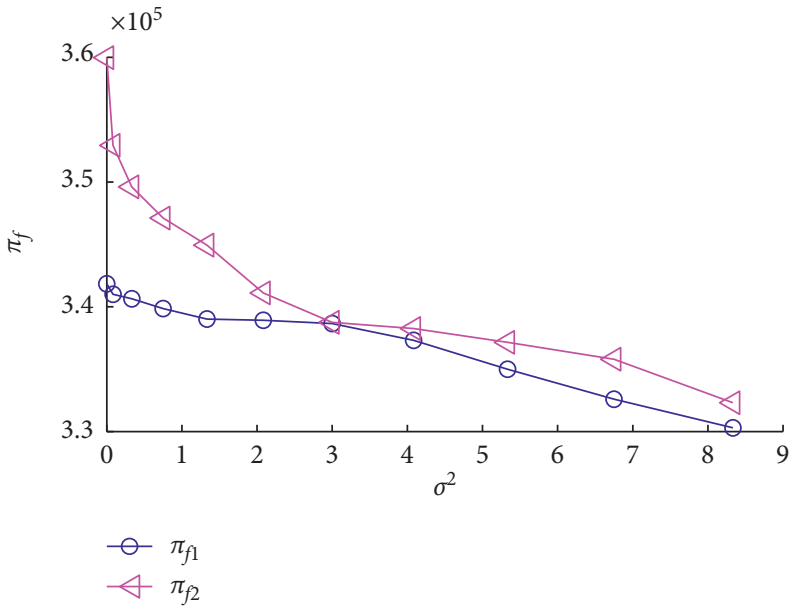

(b)

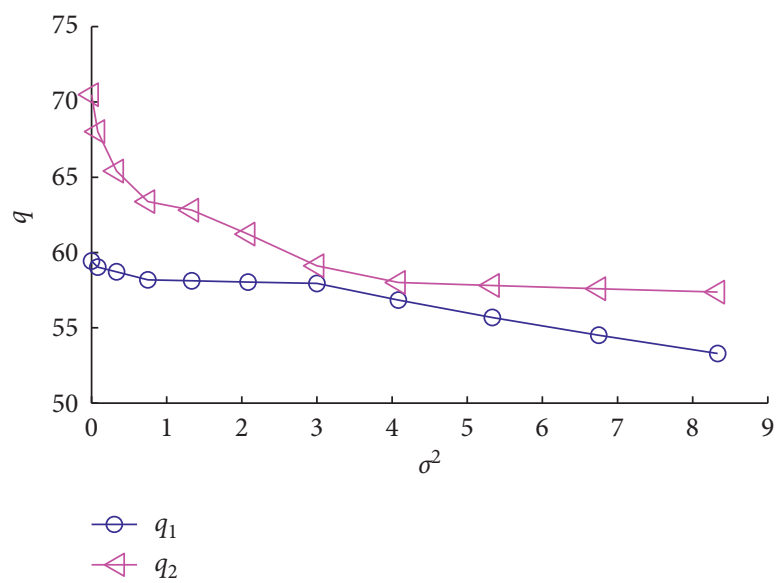

(d)

FIGURE 5: Effects of random risk of yield on the family farm and food processing enterprise when bank financing.

It can be observed intuitively from Tables $1-3$ that the profits of the family farm and the food processing enterprise in the case of no financing are far greater than those in the case of financing under the same random risk of yield, which indicates that the costs generated in the financing process cannot be ignored.

6.4. Effects of Random Risk of Yield on the Family Farm and Food Processing Enterprise When Bank Financing. As shown in Figure 5(a)-5(d) in the case of bank financing, when the minimum purchase price policy is not considered, as the risk of yield uncertainty increases, the family farm will reduce the input amount, and the food processing enterprise will reduce the purchase price. Meanwhile, the profits of the family farm and food processing enterprise will decrease as the risk of yield uncertainty increases. This verifies Corollary 2 and Corollary 3.

From Figure 5(a), it can be seen that the profit of the food processing enterprise when "government, bank, and insurance" participate together is obviously greater than when only the bank participates. From Figure 5(b), it can be seen that the profit of family farms when "government, bank, and insurance" participate together is greater than when only banks participate. It can be observed from Figure 5(a) and Figure 5(b) that the welfare improvement of the food processing enterprise in the case of bank financing with "government, bank, and insurance" coparticipation is more significant than that of the family farm.

As can be seen from Figure 5(c), the purchase price in the case of bank financing with "government, bank, and insurance" coparticipation is lower than that in the case of bank financing with bank participation only. The possible reason is that the food processing enterprise has the obligation to guarantee the loan repayment in the case of bank financing with bank participation only, and the purchase price is moderately increased to encourage the family farm to repay the loan. At the same time, we have learned from the foregoing analysis that $w_{1}^{*}=m c\left(1+r_{1}\right) /\left(2 c\left(1+r_{1}\right)+\beta\left(\sigma^{2}+\right.\right.$ $\left.\left.\mu^{2}\right)\right)$ and $w_{2}^{*}=m c\left[1+(1+s) r_{2}\right] /\left\{2 c\left[1+(1+s) r_{2}\right]+\beta\left(\sigma^{2}+\right.\right.$ $\left.\left.\mu^{2}\right)+b(1-j)\left(1+r_{2}\right) c\right\}$, and $w_{1}^{*}>w_{2}^{*}$ can be obtained, which is consistent with the graphic description. It can be seen from Figure 5(d) that the input amount of the family farm in the case of bank financing with "government, bank, and insurance" coparticipation is greater than that in the case of bank financing with bank participation only. Meanwhile, it 
can be seen that the greater or smaller the risk of yield uncertainty is, the more favorable the bank financing with "government, bank, and insurance" coparticipation is to the family farm.

\section{Conclusion}

In this study, the optimal bank financing decisions for a twoechelon contract food supply chain composed of a family farm with capital constraints and a food processing enterprise are analyzed. We consider both the bank financing with "government, bank, and insurance" coparticipation and the bank financing with bank participation only which has been widely used in the manufacturing industry. At the same time, the case of sufficient supply chain funds is used as the benchmark model, and we find that the profits of supply chain members in the benchmark case are far greater than that in the financing case, which indicates that the financing cost cannot be ignored. This is consistent with the actual operation of enterprises, where "financing difficulty" and "financing expensive" are common, especially for SMEs. The yield random factor is introduced into the model to measure yield uncertainty, which is different from the measurement of yield uncertainty by Huang and Lin [7]. We also conduct theoretical discussions on government subsidies. Given the exogenous variables, the improvement of the welfare of supply chain members is more obvious when bank financing with "government, bank, and insurance" coparticipation than when bank financing with bank participation only, indicating that the loan interest rate and the risk of repayment in the supply chain are reduced when bank financing with "government, bank, and insurance" coparticipation, which is consistent with the conclusion of Huang and Lin [7]. Under the same risk of yield uncertainty, the profits of supply chain members in bank financing with "government, bank, and insurance" coparticipation are significantly higher than the profits in bank financing with bank participation only, indicating that government subsidies improve the profits of members of the supply chain, which is consistent with the conclusion of Ye et al. [38]. Meanwhile, we consider the minimum purchase price policy in the model. Numerical examples show that the profit of the family farm is much higher than that without the minimum purchase price policy when the price is too low. It indicates that the implementation of the minimum purchase price policy increases the welfare of the family farm, which improves the enthusiasm of the family farm, and ensures national food security. Therefore, it is of practical significance for the government to participate in the financing process of the food supply chain $[7,16,38]$.

Some management implications are as follows: first, contract farming should be vigorously developed based on the special properties of the food, which will increase the income of the farmers [25-33], improve their enthusiasm for growing, and then ensure national food security. At present, the contract farming mode of "company + farmer" and "company + farmer cooperative + farmer" has been practiced in China. The government encourages leading enterprises to extend the industrial chain, guarantee the supply chain, and improve the interest chain by means of "company + farmers" and "company + farmer cooperatives + farmers", so as to bring small farmers into the modern agricultural industrial system. Second, financing in a capitalconstrained supply chain will improve the welfare of the supply chain members while the costs incurred in the financing process cannot be ignored $[9,37]$, so financing will be an optimal choice for the capital-constrained supply chain. Third, it is necessary to promote the bank financing with "government, bank, and insurance" coparticipation model to solve the problem of financial constraints in the food supply chain. In fact, the bank financing with "government, bank, and insurance" coparticipation has been applied in the agricultural supply chain. For example, Sanshui District People's Government of Foshan City, Guangdong Province, China, Sanshui Rural Credit Cooperative Association of Sanshui District, and People's Insurance Company of China (PICC) Foshan Sanshui Branch signed a tripartite agreement to explore a new agricultural loan model of "government-bank-insurance" cooperation in July 2009. And Sanshui "government-bank-insurance" cooperation mode was proved to be an effective way to solve the farmers' loans difficult after more than eight-year practice, which made the "government-bank-insurance" loans in Sanshui District exceed 900 million yuan, benefiting more than 5000 peasant households by 2016, while the district finance only invested a total of 8.5 million yuan in premium subsidies but promoted more than 900 million social capital investment in agricultural production, which played a leverage role of the financial fund. Therefore, it is of great practical significance to explore the bank financing mechanism of the "government-bank-insurance" cooperation in the capital-constrained contract farming supply chain.

There are several limitations in the study, which may be worth further exploration. First, the family farm produces only a single variety of rice in our study, and it may be interesting to consider that the family farm produces multiple varieties of food in the future. Second, we consider a two-echelon contract food supply chain composed of a family farm with capital constraints and a food processing enterprise in the study; however, selecting multiple suppliers is one of the effective ways to deal with random yield for the downstream of the supply chain since agricultural production is susceptible to natural conditions and the yield is uncertain [10-14], so the optimal financing decisions for a two-echelon contract food supply chain composed of two or more family farms with capital constraints and a food processing enterprise can be explored in the future. Thirdly, blockchain technology is not involved in this study, and future research can explore how to reduce financing risks through blockchain [45].

\section{Appendix}

\section{Proof of Proposition 1}

The expected profit of the family farm is shown in the following equation: 


$$
E \pi_{f 0}=w_{0} q_{0} \mu-c q_{0}^{2} .
$$

The optimal planned input of the family farm can be obtained in equation (A.2) by solving the first derivative of $q_{0}$ of $E \pi_{f 0}$ and setting it equal to 0 :

$$
q_{0}^{*}=\frac{w_{0} \mu}{2 c}
$$

The expected profit of the food processing enterprise is shown as follows:

$$
E \pi_{m 0}=m q_{0} \mu-w_{0} q_{0} \mu+\beta q_{0}^{2}\left(\sigma^{2}+\mu^{2}\right) .
$$

After substituting $q_{0}^{*}=w_{0} \mu /(2 c)$ into equation (A.3), we can obtain the optimal purchase price of the food processing enterprise in equation (A.4) by solving the first derivative of $w_{0}$ of $E \pi_{m 0}$ and setting it equal to 0 :

$$
w_{0}^{*}=\frac{m c}{2 c-\beta\left(\sigma^{2}+\mu^{2}\right)} .
$$

Due to the quasi-public property of food, when the rice price is too low, government participates in regulation and sets the minimum purchase price; that is, the food processing enterprise purchases rice from the family farm at the minimum purchase price when $w_{0}<w$.

It is easy to obtain the optimal planned input of the family farm by substituting $w_{0}^{*}=m c /\left[2 c-\beta\left(\sigma^{2}+\mu^{2}\right)\right]$ into equation (A.2) as follows:

$$
q_{0}^{*}=\frac{m \mu}{4 c-2 p\left(\sigma^{2}+\mu^{2}\right)} .
$$

\section{Proof of Corollary 1}

We solve the first derivative of equation (A.5) and obtain the following result:

$$
\frac{\mathrm{d} q_{0}^{*}}{\mathrm{~d} \sigma^{2}}=\frac{2 \beta m \mu}{\left[4 c-2 \beta\left(\sigma^{2}+\mu^{2}\right)\right]^{2}}>0 .
$$

According to equation (A.6), the family farm will expand the growing scale as the risk of yield uncertainty increases.

Other results can be drawn as well in the following:

$$
\begin{aligned}
\frac{\mathrm{d} w_{0}^{*}}{\mathrm{~d} \sigma^{2}} & =\frac{\beta m c}{\left[2 c-\beta\left(\sigma^{2}+\mu^{2}\right)\right]^{2}}>0, \\
\frac{\mathrm{d} E \pi_{f 0}^{*}}{\mathrm{~d} \sigma^{2}} & =\frac{-m^{2} \mu^{2} c\left(8 \beta^{2} \sigma^{2}+8 \beta^{2} \mu^{2}-4 c \beta\right)}{16\left[2 c-\beta\left(\sigma^{2}+\mu^{2}\right)\right]^{4}}>0, \\
\frac{\mathrm{d} E \pi_{m 0}^{*}}{\mathrm{~d} \sigma^{2}} & =\frac{4 \beta m^{2} \mu^{2}}{16\left[2 c-\beta\left(\sigma^{2}+\mu^{2}\right)\right]^{2}}>0 .
\end{aligned}
$$

According to equations (A.7)-(A.9), we can draw that with the increase of the risk of yield uncertainty, the food processing enterprise will increase the purchase price, and his profit will increase accordingly, but the profit of the family farm will decrease.
Proof of Proposition 2

We define $F_{1}\left(r_{1}, r_{f}\right)$ and solve the first derivative of $F_{1}\left(r_{1}, r_{f}\right)$ as follows:

$$
\begin{aligned}
F_{1}\left(r_{1}, r_{f}\right)= & \int_{\mathrm{d}_{1}}^{\mathrm{d}_{t h}} w_{1} q_{1} x g(x) \mathrm{d} x \\
& +\int_{\mathrm{d}_{t h}}^{\mathrm{d}_{2}}\left(1+r_{1}\right) R_{1} g(x) \mathrm{d} x-R_{1}\left(1+r_{f}\right),
\end{aligned}
$$

$\frac{\partial F_{1} R_{1}, r\left(R_{1}\right)}{\partial r_{1}}=R_{1} \overline{F_{1}}\left(\frac{\left(1+r_{1}\right) R_{1}}{q_{1} w_{1}}\right)$

$\frac{\partial F_{1} R_{1}, r\left(R_{1}\right)}{\partial r_{f}}=-R_{1}$

The expression of $\mathrm{d} r / \mathrm{d} r_{f}$ can be obtained as follows according to the definition of elasticity:

$$
\frac{\mathrm{d} r_{1}}{\mathrm{~d} r_{f}}=-\frac{\partial F_{1} R_{1}, r\left(R_{1}\right) / \partial r_{f}}{\partial F_{1} R_{1}, r\left(R_{1}\right) / \partial r_{1}}=1 / \overline{F_{1}}\left(\frac{\left(1+r_{1}\right) R_{1}}{q_{1} w_{1}}\right) .
$$

We can observe that $\mathrm{d} r / \mathrm{d} r_{a}>0$ from equation (A.13), so Proposition 2 is proved.

\section{Proof of Proposition 3}

We can obtain the optimal planned input of the family farm when bank financing with bank participation only from equation (15) by solving the first derivative of $q_{1}$ of $E \pi_{f 1}$ and setting it equal to 0 :

$$
q_{1}^{*}=\frac{w_{1} \mu}{2 c\left(1+r_{1}\right)}
$$

We obtain equation (A.15) after substituting $q_{1}^{*}=w_{1} \mu / 2 c\left(1+r_{1}\right)$ into equation (18) and solve the first derivative of $w_{1}$ as follows:

$$
\begin{gathered}
E \pi_{m 1}=\frac{m w_{1} \mu^{2}}{2 c\left(1+r_{1}\right)}-\frac{w_{1}^{2} \mu^{2}}{2 c\left(1+r_{1}\right)}-\frac{w_{1}^{2} \mu^{2} \beta\left(\sigma^{2}+\mu^{2}\right)}{4 c^{2}\left(1+r_{1}\right)^{2}}, \\
\frac{\mathrm{dE} \pi_{m 1}}{\mathrm{~d} w_{1}}=\frac{m \mu^{2}}{2 c\left(1+r_{1}\right)}-\frac{\mu^{2} w_{1}}{c\left(1+r_{1}\right)}-\frac{\mu^{2} \beta\left(\sigma^{2}+\mu^{2}\right) w_{1}}{2 c^{2}\left(1+r_{1}\right)^{2}} .
\end{gathered}
$$

Let equation $(\mathrm{A} .16)=0$, and we can obtain the optimal purchase price of the food processing enterprise in the following:

$$
w_{1}^{*}=\frac{m c\left(1+r_{1}\right)}{2 c\left(1+r_{1}\right)+\beta\left(\sigma^{2}+\mu^{2}\right)} .
$$

Due to the quasi-public property of food, when the rice price is too low, government participates in regulation and sets the minimum purchase price; that is, the food processing enterprise purchases rice from the family farm at the minimum purchase price when $w_{1}<w$. 
It is easy to obtain the optimal planned input of the family farm by substituting $w_{1}^{*}=m c\left(1+r_{1}\right) /\left[2 c\left(1+r_{1}\right)+\right.$ $\left.\beta\left(\sigma^{2}+\mu^{2}\right)\right]$ into equation (A.14) as follows:

$$
q_{1}^{*}=\frac{m \mu}{2\left[2 c\left(1+r_{1}\right)+\beta\left(\sigma^{2}+\mu^{2}\right)\right]} .
$$

Proof of Corollary 2

We solve the first derivative of $q_{1}^{*}, w_{1}^{*}, E \pi_{f 1}^{*}$, and $E \pi_{m 1}^{*}$ as follows:

$$
\frac{\mathrm{d} q_{1}^{*}}{\mathrm{~d} \sigma^{2}}=\frac{-2 \beta m \mu}{4\left[2 c\left(1+r_{1}\right)+\beta\left(\sigma^{2}+\mu^{2}\right)\right]^{2}}<0 .
$$

Other results can be drawn as well in the following:

$$
\begin{aligned}
\frac{\mathrm{d} w_{1}^{*}}{\mathrm{~d} \sigma^{2}} & =\frac{-\beta m c\left(1+r_{1}\right)}{\left[2 c\left(1+r_{1}\right)+\beta\left(\sigma^{2}+\mu^{2}\right)\right]^{2}}<0, \\
\frac{\mathrm{d} E \pi_{f 1}^{*}}{\mathrm{~d} \sigma^{2}} & =\frac{-m^{2} \mu^{2} c\left(1+r_{1}\right)\left[8 c\left(1+r_{1}\right)+8 \beta^{2}\left(\sigma^{2}+\mu^{2}\right)\right]}{16\left[2 c\left(1+r_{1}\right)+\beta\left(\sigma^{2}+\mu^{2}\right)\right]^{4}}<0, \\
\frac{\mathrm{d} E \pi_{m 1}^{*}}{\mathrm{~d} \sigma^{2}} & =\frac{-4 m^{2} \mu^{2} \beta}{16\left[2 c\left(1+r_{1}\right)+\beta\left(\sigma^{2}+\mu^{2}\right)\right]^{2}}<0
\end{aligned}
$$

According to equation (A.20)-(A.22), Corollary 2 is proved.

\section{Proof of Proposition 4}

Solve the first derivative of $E \pi_{f 2}$, and set it equal to 0:

$$
\begin{aligned}
q_{2}^{*} & =\frac{w_{2} \mu}{2 c\left[1+(1-s) r_{2}\right]}, \\
\pi_{m 2} & =p_{2} q_{2} X-w_{2} q_{2} X-b(1-j)\left(1+r_{2}\right) c q_{2}^{2} \\
& =\left(m-\beta q_{2} X\right) q_{2} X-w_{2} q_{2} X-b(1-j)\left(1+r_{2}\right) c q_{2}^{2} \\
& =m q_{2} X-w_{2} q_{2} X-\beta q_{2}^{2} X^{2}-b(1-j)\left(1+r_{2}\right) c q_{2}^{2} .
\end{aligned}
$$

Then, we can obtain $E \pi_{m 2}$ as follows:

$$
E \pi_{m 2}=m q_{2} \mu-w_{2} q_{2} \mu-\beta q_{2}^{2}\left(\sigma^{2}+\mu^{2}\right)-b(1-j)\left(1+r_{2}\right) c q_{2}^{2} .
$$

We obtain equation (A.26) after substituting $q_{2}^{*}=w_{2} \mu /\left\{2 c\left[1+(1-s) r_{2}\right]\right\}$ into equation (A.25) and solve the first derivative of $E \pi_{m 2}$ as follows:

$$
\begin{aligned}
E \pi_{m 2} & =\frac{m \mu^{2} w_{2}}{2 c\left[1+(1-s) r_{2}\right]}-\frac{\left\{2 c\left[1+(1-s) r_{2}\right]+\beta\left(\sigma^{2}+\mu^{2}\right)+b(1-j)\left(1+r_{2}\right) c\right\} \mu^{2} w_{2}^{2}}{\left\{2 c\left[1+(1-s) r_{2}\right]\right\}^{2}}, \\
\frac{\mathrm{dE} \pi_{m 2}}{\mathrm{~d} w_{2}} & =\frac{m \mu^{2}}{2 c\left[1+(1-s) r_{2}\right]}-\frac{2\left\{2 c\left[1+(1-s) r_{2}\right]+\beta\left(\sigma^{2}+\mu^{2}\right)+b(1-j)\left(1+r_{2}\right) c\right\} \mu^{2} w_{2}}{\left\{2 c\left[1+(1-s) r_{2}\right]\right\}^{2}} .
\end{aligned}
$$

Let equation $(\mathrm{A} .27)=0$, and we can obtain the optimal purchase price of the food processing enterprise in the following:

$$
w_{2}^{*}=\frac{m c\left[1+(1-s) r_{2}\right]}{\left\{2 c\left[1+(1-s) r_{2}\right]+\beta\left(\sigma^{2}+\mu^{2}\right)+b(1-j)\left(1+r_{2}\right) c\right\}} .
$$

Due to the quasi-public property of food, when the rice price is too low, government participates in regulation and sets the minimum purchase price; that is, the food processing enterprise purchases rice from the family farm at the minimum purchase price when $w_{2}<w$.

It is easy to obtain the optimal planned input of the family farm by substituting $w_{2}^{*}=m c\left[1+(1-s) r_{2}\right] /$ $\left\{2 c\left[1+(1-s) r_{2}\right]+\beta\left(\sigma^{2}+\mu^{2}\right)+b(1-j)\left(1+r_{2}\right) c\right\} \quad$ into equation (A.23) as follows:

$$
q_{2}^{*}=\frac{w_{2} \mu}{2 c\left[1+(1-s) r_{2}\right]}=\frac{m \mu}{2\left\{2 c\left[1+(1-s) r_{2}\right]+\beta\left(\sigma^{2}+\mu^{2}\right)+b(1-j)\left(1+r_{2}\right) c\right\}} .
$$




$$
\begin{aligned}
\frac{\mathrm{d} q_{2}^{*}}{\mathrm{~d} \sigma^{2}} & =\frac{-\beta m \mu}{2\left\{2 c\left[1+(1-s) r_{2}\right]+\beta\left(\sigma^{2}+\mu^{2}\right)+b(1-j)\left(1+r_{2}\right) c\right\}^{2}}<0, \\
\frac{\mathrm{d} w_{2}^{*}}{\mathrm{~d} \sigma^{2}} & =\frac{-\beta m c\left[1+(1-s) r_{2}\right]}{\left\{2 c\left[1+(1-s) r_{2}\right]+\beta\left(\sigma^{2}+\mu^{2}\right)+b(1-j)\left(1+r_{2}\right) c\right\}^{2}}<0, \\
\frac{\mathrm{d} E \pi_{f 2}^{*}}{\mathrm{~d} \sigma^{2}} & =\frac{-m^{2} c \mu^{2}\left[1+(1-s) r_{2}\right]\left\{2 \beta \sigma^{2}+2 \mu^{2}+4 c \beta\left[1+(1-s) r_{2}\right]+\beta b(1-j)\left(1+r_{2}\right) c\right\}}{16\left\{2 c\left[1+(1-s) r_{2}\right]+\beta\left(\sigma^{2}+\mu^{2}\right)+b(1-j)\left(1+r_{2}\right) c\right\}^{4}}<0, \\
\frac{\mathrm{d} E \pi_{m 2}^{*}}{\mathrm{~d} \sigma^{2}} & =\frac{-4 \beta \mu^{2} m^{2}}{16\left\{2 c\left[1+(1-s) r_{2}\right]+\beta\left(\sigma^{2}+\mu^{2}\right)+b(1-j)\left(1+r_{2}\right) c\right\}^{2}}<0 .
\end{aligned}
$$

According to equations (A.30)-(A.33), Corollary 3 is proved.

\section{Data Availability}

The data used to support the findings of this study are included within the article.

\section{Conflicts of Interest}

The authors declared that there are no conflicts of interest.

\section{Acknowledgments}

This research was supported by the National Social Science Foundation of China (\#20BJY148, \#19BGL153, and \#17BGL057), the Key Research and Development Program of Hunan Province of China (grant nos. 2017SK2345 and 2018GK2073), and Fundamental Research Funds for the Central Universities (JBK1507105).

\section{References}

[1] H.-C. Pfohl and M. Gomm, "Supply chain finance: optimizing financial flows in supply chains," Logistics Research, vol. 1, no. 3-4, pp. 149-161, 2009.

[2] X. Xu, X. Chen, F. Jia, S. Brown, Y. Gong, and Y. Xu, "Supply chain finance: a systematic literature review and bibliometric analysis," International Journal of Production Economics, vol. 204, pp. 160-173, 2018.

[3] E. Hofmann and H. Kotzab, "A supply chain-oriented approach of working capital management," Journal of Business Logistics, vol. 31, no. 2, pp. 305-330, 2010.

[4] M. Wandfluh, E. Hofmann, and P. Schoensleben, "Financing buyer-supplier dyads: an empirical analysis on financial collaboration in the supply chain," International Journal of Logistics Research and Applications, vol. 19, no. 3, pp. 200-217, 2016.

[5] C. Wang, F. Yu, Z. Zhang, and J. Zhang, "Multiview graph learning for small-and medium-sized enterprises' credit risk assessment in supply chain finance," Complexity, vol. 202113 pages, 2021.
[6] N. Yan, B. Sun, and B. Sun, "Comparative analysis of supply chain financing strategies between different financing modes," Journal of Industrial \& Management Optimization, vol. 11, no. 4, pp. 1073-1087, 2015.

[7] J. Huang and Q. Lin, "Government subsidy mechanism in contract-farming supply chain financing under loan guarantee insurance and yield uncertainty," Chinese Journal of Management Science, vol. 27, no. 3, pp. 53-65, 2019.

[8] Y. He and X. Zhao, "Coordination in multi-echelon supply chain under supply and demand uncertainty," International Journal of Production Economics, vol. 139, no. 1, pp. 106-115, 2012.

[9] W. Ding and G. Wan, "Financing and coordinating the supply chain with a capital-constrained supplier under yield uncertainty," International Journal of Production Economics, vol. 230, p. 107813, 2020.

[10] H. Gurnani, K. Ramachandran, S. Ray, and Y. Xia, "Ordering behavior under supply risk:an experimental investigation," Manufacturing \& Service Operations Management, vol. 16, no. 1, pp. 61-75, 2014.

[11] J. He, F. Alavifard, D. Ivanov, and H. Jahani, "A real-option approach to mitigate disruption risk in the supply chain," Omega, vol. 88, pp. 133-149, 2019.

[12] C.-C. Hsieh and H.-H. Lai, "Pricing and ordering decisions in a supply chain with downward substitution and imperfect process yield," Omega, vol. 95, p. 102064, 2020.

[13] B. Niu, J. Li, J. Zhang, H. K. Cheng, and Y. R. Tan, "Strategic analysis of dual sourcing and dual channel with an unreliable alternative supplier," Production and Operations Management, vol. 28, no. 3, pp. 570-587, 2019.

[14] X. Yuan, G. Bi, Y. Fei, and L. Liu, "Supply chain random yield and financing," Omega, vol. 102, Article ID 102334, 2020.

[15] B. Kazaz and S. Webster, "The impact of yield-dependent trading costs on pricing and production planning under supply uncertainty," Manufacturing \& Service Operations Management, vol. 13, no. 3, pp. 404-417, 2011.

[16] H. Peng and T. Pang, "Optimal strategies for a three-level contract-farming supply chain with subsidy," International Journal of Production Economics, vol. 216, pp. 274-286, 2019.

[17] F. Ye, Q. Lin, and Y. Li, “Coordination for contract farming supply chain with stochastic yield and demand under CVaR 
criterion," Operational Research, vol. 20, no. 1, pp. 369-397, 2020 b.

[18] X. Liu, X. Shen, and M. You, "Study on coordination and optimization of contract farming supply chain based on uncertain conditions," Scientific Programming, vol. 2020, Article ID 8858812, 9 pages, 2020.

[19] Q. F. Zhang, "The political economy of contract farming in China's agrarian transition," Journal of Agrarian Change, vol. 12, no. 4, pp. 460-483, 2012.

[20] D. Wuepper and J. Sauer, "Explaining the performance of contract farming in Ghana: the role of self-efficacy and social capital," Food Policy, vol. 62, pp. 11-27, 2016.

[21] M. F. Bellemare and L. Novak, "Contract farming and food security," American Journal of Agricultural Economics, vol. 99, no. 2, pp. 357-378, 2017.

[22] Z. Shi and E. Cao, "Contract farming problems and games under yield uncertainty," Australian Journal of Agricultural and Resource Economics, vol. 64, no. 4, pp. 1210-1238, 2020.

[23] H. A. Ba, Y. de Mey, S. Thoron, and M. Demont, "Inclusiveness of contract farming along the vertical coordination continuum: evidence from the Vietnamese rice sector," Land Use Policy, vol. 87, p. 104050, 2019.

[24] D. Zhang, "The innovation research of contract farming financing mode under the block chain technology," Journal of Cleaner Production, vol. 270, p. 122194, 2020.

[25] A. Arouna, J. D. Michler, and J. C. Lokossou, "Contract farming and rural transformation: evidence from a field experiment in Benin," Journal of Development Economics, vol. 151, p. 102626, 2021.

[26] M. F. Bellemare, "As you sow, so shall you reap: the welfare impacts of contract farming," World Development, vol. 40, no. 7, pp. 1418-1434, 2012.

[27] M. F. Bellemare and J. R. Bloem, "Does contract farming improve welfare? a review," World Development, vol. 112, pp. 259-271, 2018.

[28] M. F. Bellemare, Y. N. Lee, and L. Novak, "Contract farming as partial insurance," World Development, vol. 140, p. 105274, 2021.

[29] A. K. Mishra, A. Kumar, P. K. Joshi, A. D’Souza, and G. Tripathi, "How can organic rice be a boon to smallholders? Evidence from contract farming in India," Food Policy, vol. 75, pp. 147-157, 2018.

[30] B. Niu, D. Jin, and X. Pu, "Coordination of channel members' efforts and utilities in contract farming operations," European Journal of Operational Research, vol. 255, no. 3, pp. 869-883, 2016.

[31] G. Soullier and P. Moustier, "Impacts of contract farming in domestic grain chains on farmer income and food insecurity. Contrasted evidence from Senegal," Food Policy, vol. 79, pp. 179-198, 2018.

[32] G. Ton, W. Vellema, S. Desiere, S. Weituschat, and M. D'Haese, "Contract farming for improving smallholder incomes: what can we learn from effectiveness studies?" World Development, vol. 104, pp. 46-64, 2018.

[33] S. J. Väth, S. Gobien, and M. Kirk, "Socio-economic wellbeing, contract farming and property rights: evidence from Ghana," Land Use Policy, vol. 81, pp. 878-888, 2019.

[34] S. Deng, C. Gu, G. Cai, and Y. Li, "Financing multiple heterogeneous suppliers in assembly systems: buyer finance vs. bank finance," Manufacturing \& Service Operations Management, vol. 20, no. 1, pp. 53-69, 2018.

[35] P. Kouvelis and W. Zhao, "Financing the newsvendor: supplier vs. bank, and the structure of optimal trade credit contracts," Operations Research, vol. 60, no. 3, pp. 566-580, 2012.

[36] P. Kouvelis and W. Zhao, "Who should finance the supply chain? Impact of credit ratings on supply chain decisions," Manufacturing \& Service Operations Management, vol. 20, no. 1, pp. 19-35, 2018.

[37] Y. Luo, Q. Wei, Q. Ling, and B. Huo, "Optimal decision in a green supply chain: bank financing or supplier financing," Journal of Cleaner Production, vol. 271, p. 122090, 2020.

[38] F. Ye, Z. Cai, Y. J. Chen, Y. Li, and G. Hou, "Subsidize farmers or bioenergy producer? The design of a government subsidy program for a bioenergy supply chain," Naval Research Logistics, pp. 1-16, 2020a.

[39] X. Zhang, P. Qing, and X. Yu, "Short supply chain participation and market performance for vegetable farmers in China," Australian Journal of Agricultural and Resource Economics, vol. 63, no. 2, pp. 282-306, 2019.

[40] M. van Bergen, M. Steeman, M. Reindorp, and L. Gelsomino, "Supply chain finance schemes in the procurement of agricultural products," Journal of Purchasing and Supply Management, vol. 25, no. 2, pp. 172-184, 2019.

[41] B. Yan, G. Liu, Z. Zhang, and C. Yan, "Optimal financing and operation strategy of fresh agricultural supply chain," Australian Journal of Agricultural and Resource Economics, vol. 64, no. 3, pp. 776-794, 2020.

[42] Z. Yi, Y. Wang, and Y. J. Chen, "Financing an agricultural supply chain with a capital-constrained smallholder farmer in developing economies," Production and Operations Management, pp. 1-20, 2021.

[43] B. Jing and A. Seidmann, "Finance sourcing in a supply chain," Decision Support Systems, vol. 58, pp. 15-20, 2014.

[44] Q. Lin and J. He, "Supply chain contract design considering the supplier's asset structure and capital constraints," Computers \& Industrial Engineering, vol. 137, Article ID 106044, 2019.

[45] R. Wang and Y. Wu, "Application of blockchain technology in supply chain finance of beibu gulf region," Mathematical Problems in Engineering, vol. 2021, Article ID 5556424, 10 pages, 2021. 